\title{
Coupled coincidence points for monotone operators in partially ordered metric spaces
}

\author{
Abdullah Alotaibi and Saud M Alsulami
}

* Correspondence:

mathker11@hotmail.com

Department of Mathematics, King

Abdulaziz University, P.O. Box

80203, Jeddah 21589, Saudi Arabia

\section{Abstract \\ Using the notion of compatible mappings in the setting of a partially ordered metric space, we prove the existence and uniqueness of coupled coincidence points involving a $(\varphi, \psi)$-contractive condition for a mappings having the mixed $g$-monotone property. We illustrate our results with the help of an example.}

Keywords: coupled coincidence point, partially ordered metric space, mixed g-monotone property

\section{Introduction}

The Banach contraction principle is the most celebrated fixed point theorem. Afterward many authors obtained many important extensions of this principle (cf. [1-16]). Recently Bhaskar and Lakshmikantham [5], Nieto and Lopez [12,13], Ran and Reurings [14] and Agarwal et al. [3] presented some new results for contractions in partially ordered metric spaces. Bhaskar and Lakshmikantham [5] noted that their theorem can be used to investigate a large class of problems and have discussed the existence and uniqueness of solution for a periodic boundary value problem.

Recently, Luong and Thuan [11] presented some coupled fixed point theorems for a mixed monotone mapping in a partially ordered metric space which are generalizations of the results of Bhaskar and Lakshmikantham [5]. In this paper, we establish the existence and uniqueness of coupled coincidence point involving a $(\varphi, \psi)$-contractive condition for mappings having the mixed $g$-monotone property. We also illustrate our results with the help of an example.

\section{Preliminaries}

A partial order is a binary relation $\preccurlyeq$ over a set $X$ which is reflexive, antisymmetric, and transitive. Now, let us recall the definition of the monotonic function $f: X \rightarrow X$ in the partially order set $(X, \preccurlyeq)$. We say that $f$ is non-decreasing if for $x, y \in X, x \leqslant y$, we have $f x \leqslant f y$. Similarly, we say that $f$ is non-increasing if for $x, y \in X, x \leqslant y$, we have $f x$ $\geqslant f y$. Any one could read on [9] for more details on fixed point theory.

Definition 2.1 [10](Mixed g-Monotone Property)

Let $(X, \preccurlyeq)$ be a partially ordered set and $F: X \times X \rightarrow X$. We say that the mapping $F$ has the mixed g-monotone property if $F$ is monotone g-non-decreasing in its first argument and is monotone $g$-non-increasing in its second argument. That is, for any $x, y \in X$,

(c) 2011 Alotaibi and Alsulami; licensee Springer. This is an Open Access article distributed under the terms of the Creative Commons Attribution License (http://creativecommons.org/licenses/by/2.0), which permits unrestricted use, distribution, and reproduction in any medium, provided the original work is properly cited. 


$$
x_{1}, x_{2} \in X, g x_{1} \preccurlyeq g x_{2} \Rightarrow F\left(x_{1}, y\right) \preccurlyeq F\left(x_{2}, y\right)
$$

and

$$
y_{1}, y_{2} \in X, g y_{1} \preccurlyeq g y_{2} \Rightarrow F\left(x, y_{1}\right) \succcurlyeq F\left(x, y_{2}\right) .
$$

Definition 2.2 [10](Coupled Coincidence Point)

Let $(x, y) \in X \times X, F: X \times X \rightarrow X$ and $g: X \rightarrow X$. We say that $(x, y)$ is a coupled coincidence point of $F$ and $g$ if $F(x, y)=g x$ and $F(y, x)=$ gy for $x, y \in X$.

Definition 2.3 [10] Let $X$ be a non-empty set and let $F: X \times X \rightarrow X$ and $g: X \rightarrow X$. We say $F$ and $g$ are commutative if, for all $x, y \in X$,

$$
g(F(x, y))=F(g(x), g(y)) .
$$

Definition 2.4 [6] The mapping $F$ and $g$ where $F: X \times X \rightarrow X$ and $g: X \rightarrow X$, are said to be compatible if

$$
\lim _{n \rightarrow \infty} d\left(g\left(F\left(x_{n}, y_{n}\right)\right), F\left(g x_{n}, g y_{n}\right)\right)=0
$$

and

$$
\lim _{n \rightarrow \infty} d\left(g\left(F\left(y_{n}, x_{n}\right)\right), F\left(g y_{n}, g x_{n}\right)\right)=0,
$$

whenever $\left\{x_{n}\right\}$ and $\left\{y_{n}\right\}$ are sequences in $X$, such that $\lim _{n \rightarrow \infty} F\left(x_{n}, y_{n}\right)=\lim _{n \rightarrow \infty} g x_{n}=$ $x$ and $\lim _{n \rightarrow \infty} F\left(y_{n}, x_{n}\right)=\lim _{n \rightarrow \infty} g y_{n}=y$, for all $x, y \in X$ are satisfied.

\section{Existence of coupled coincidence points}

As in [11], let $\varphi$ denote all functions $\varphi:[0, \infty) \rightarrow[0, \infty)$ which satisfy

1. $\varphi$ is continuous and non-decreasing,

2. $\varphi(t)=0$ if and only if $t=0$,

3. $\varphi(t+s) \leq \varphi(t)+\varphi(s), \forall t, s \in[0, \infty)$

and let $\psi$ denote all the functions $\psi:[0, \infty) \rightarrow(0, \infty)$ which satisfy $\lim _{t \rightarrow r} \psi(t)>0$ for all $r>0$ and $\lim _{t \rightarrow 0^{+}} \psi(t)=0$.

For example [11], functions $\varphi_{1}(t)=k t$ where $k>0, \phi_{2}(t)=\frac{t}{t+1}, \varphi_{3}(t)=\ln (t+1)$, and $\varphi_{4}(t)=\min \{t, 1\}$ are in $\boldsymbol{\Phi} ; \psi_{1}(t)=k t$ where $k>0, \psi_{2}(t)=\frac{\ln (2 t+1)}{2}$, and

$$
\psi_{3}(t)= \begin{cases}1, & t=0 \\ \frac{t}{t+1}, & 0<t<1 \\ 1, & t=1 \\ \frac{1}{2} t, & t>1\end{cases}
$$

are in $\Psi$,

Now, let us start proving our main results.

Theorem 3.1 Let $(X, \preccurlyeq)$ be a partially ordered set and suppose there is a metric $d$ on $X$ such that $(X, d)$ is a complete metric space. Let $F: X \times X \rightarrow X$ be a mapping having the mixed $g$-monotone property on $X$ such that there exist two elements $x_{0}, y_{0} \in X$ with 


$$
g x_{0} \preccurlyeq F\left(x_{0}, y_{0}\right) \text { and } g y_{0} \succcurlyeq F\left(y_{0}, x_{0}\right) .
$$

Suppose there exist $\varphi \in \Phi$ and $\psi \in \Psi$ such that

$$
\phi(d(F(x, y), F(u, v))) \leq \frac{1}{2} \phi(d(g x, g u)+d(g y, g v))-\psi\left(\frac{d(g x, g u)+d(g y, g v))}{2}\right)
$$

for all $x, y, u, v \in X$ with $g x \geqslant g u$ and $g y \leqslant g v$. Suppose $F(X \times X) \subseteq g(X)$, $g$ is continuous and compatible with $F$ and also suppose either

(a) $F$ is continuous or

(b) $X$ has the following property:

(i) if a non-decreasing sequence $\left\{x_{n}\right\} \rightarrow x$, then $x_{n} \leqslant x$, for all $n$,

(ii) if a non-increasing sequence $\left\{y_{n}\right\} \rightarrow y$, then $y \leqslant y_{n}$, for all $n$.

Then there exists $x, y \in X$ such that

$$
g x=F(x, y) \text { and } g y=F(y, x),
$$

i.e., $F$ and $g$ have a coupled coincidence point in $X$.

Proof. Let $x_{0}, y_{0} \in X$ be such that $g x_{0} \leqslant F\left(x_{0}, y_{0}\right)$ and $g y_{0} \geqslant F\left(y_{0}, x_{0}\right)$.

Using $F(X \times X) \subseteq g(X)$, we construct sequences $\left\{x_{n}\right\}$ and $\left\{y_{n}\right\}$ in $X$ as

$$
g x_{n+1}=F\left(x_{n}, y_{n}\right) \text { and } g y_{n+1}=F\left(y_{n}, x_{n}\right) \text { for all } n \geq 0 .
$$

We are going to prove that

$$
g x_{n} \preccurlyeq g x_{n+1} \quad \text { for all } n \geq 0
$$

and

$$
g y_{n} \succcurlyeq g y_{n+1} \quad \text { for all } n \geq 0 .
$$

To prove these, we are going to use the mathematical induction.

Let $n=0$. Since $g x_{0} \leqslant F\left(x_{0}, y_{0}\right)$ and $g y_{0} \geqslant F\left(y_{0}, x_{0}\right)$ and as $g x_{1}=F\left(x_{0}, y_{0}\right)$ and $g y_{1}=F$ $\left(y_{0}, x_{0}\right)$, we have $g x_{0} \leqslant g x_{1}$ and $g y_{0} \geqslant g y_{1}$. Thus (5) and (6) hold for $n=0$.

Suppose now that (5) and (6) hold for some fixed $n \geq 0$, Then, since $g x_{n} \leqslant g x_{n+1}$ and $g y_{n} \geqslant g y_{n+1}$, and by mixed $g$-monotone property of $F$, we have

$$
g x_{n+2}=F\left(x_{n+1}, y_{n+1}\right) \succcurlyeq F\left(x_{n}, y_{n+1}\right) \succcurlyeq F\left(x_{n}, y_{n}\right)=g x_{n+1}
$$

and

$$
g y_{n+2}=F\left(y_{n+1}, x_{n+1}\right) \preccurlyeq F\left(y_{n}, x_{n+1}\right) \preccurlyeq F\left(y_{n}, x_{n}\right)=g y_{n+1} .
$$

Using (7) and (8), we get

$$
g x_{n+1} \preccurlyeq g x_{n+2} \quad \text { and } \quad g y_{n+1} \succcurlyeq g y_{n+2} \text {. }
$$

Hence by the mathematical induction we conclude that (5) and (6) hold for all $n \geq 0$. Therefore,

$$
g x_{0} \preccurlyeq g x_{1} \preccurlyeq g x_{2} \preccurlyeq \cdots \preccurlyeq g x_{n} \preccurlyeq g x_{n+1} \preccurlyeq \cdots
$$


and

$$
g y_{0} \succcurlyeq g y_{1} \succcurlyeq g y_{2} \succcurlyeq \cdots \succcurlyeq g y_{n} \succcurlyeq g y_{n+1} \succcurlyeq \cdots .
$$

Since $g x_{n} \geqslant g x_{n-1}$ and $g y_{n} \leqslant g y_{n-1}$, using (3) and (4), we have

$$
\begin{aligned}
\phi\left(d\left(g x_{n+1}, g x_{n}\right)\right) & =\phi\left(d\left(F\left(x_{n}, y_{n}\right), F\left(x_{n-1}, y_{n-1}\right)\right)\right) \\
& \leq \frac{1}{2} \phi\left(d\left(g x_{n}, g x_{n-1}\right)+d\left(g y_{n}, g y_{n-1}\right)\right) \\
& -\psi\left(\frac{d\left(g x_{n}, g x_{n-1}\right)+d\left(g y_{n}, g y_{n-1}\right)}{2}\right) .
\end{aligned}
$$

Similarly, since $g y_{n-1} \geqslant g y_{n}$ and $g x_{n-1} \leqslant g x_{n}$, using (3) and (4), we also have

$$
\begin{aligned}
\phi\left(d\left(g y_{n}, g y_{n+1}\right)\right) & =\phi\left(d\left(F\left(y_{n-1}, x_{n-1}\right), F\left(y_{n}, x_{n}\right)\right)\right) \\
& \leq \frac{1}{2} \phi\left(d\left(g y_{n-1}, g y_{n}\right)+d\left(g x_{n-1}, g x_{n}\right)\right) \\
& -\psi\left(\frac{d\left(\left(g y_{n-1}, g y_{n}\right)+d\left(g x_{n-1}, g x_{n}\right)\right.}{2}\right) .
\end{aligned}
$$

Using (11) and (12), we have

$$
\begin{aligned}
\phi\left(d\left(g x_{n+1}, g x_{n}\right)\right)+\phi\left(d\left(g y_{n+1}, g y_{n}\right)\right) & \leq \phi\left(d\left(g x_{n}, g x_{n-1}\right)+d\left(g y_{n}, g y_{n-1}\right)\right) \\
& -2 \psi\left(\frac{d\left(g x_{n}, g x_{n-1}\right)+d\left(g y_{n}, g y_{n-1}\right)}{2}\right) .
\end{aligned}
$$

By property (iii) of $\varphi$, we have

$$
\phi\left(d\left(g x_{n+1}, g x_{n}\right)+d\left(g y_{n+1}, g y_{n}\right)\right) \leq \phi\left(d\left(g x_{n+1}, g x_{n}\right)\right)+\phi\left(d\left(g y_{n+1}, g y_{n}\right)\right) .
$$

Using (13) and (14), we have

$$
\begin{aligned}
\phi\left(d\left(g x_{n+1}, g x_{n}\right)+d\left(g y_{n+1}, g y_{n}\right)\right) & \leq \phi\left(d\left(g x_{n}, g x_{n-1}\right)+d\left(g y_{n}, g y_{n-1}\right)\right) \\
& -2 \psi\left(\frac{d\left(g x_{n}, g x_{n-1}\right)+d\left(g y_{n}, g y_{n-1}\right)}{2}\right)
\end{aligned}
$$

which implies, since $\psi$ is a non-negative function,

$$
\phi\left(d\left(g x_{n+1}, g x_{n}\right)+d\left(g y_{n+1}, g y_{n}\right)\right) \leq \phi\left(d\left(g x_{n}, g x_{n-1}\right)+d\left(g y_{n}, g y_{n-1}\right)\right) .
$$

Using the fact that $\varphi$ is non-decreasing, we get

$$
d\left(g x_{n+1}, g x_{n}\right)+d\left(g y_{n+1}, g y_{n}\right) \leq d\left(g x_{n}, g x_{n-1}\right)+d\left(g y_{n}, g y_{n-1}\right) .
$$

Set

$$
\delta_{n}=d\left(g x_{n+1}, g x_{n}\right)+d\left(g y_{n+1}, g y_{n}\right) .
$$

Now we would like to show that $\delta_{n} \rightarrow 0$ as $n \rightarrow \infty$. It is clear that the sequence $\left\{\delta_{n}\right\}$ is decreasing. Therefore, there is some $\delta \geq 0$ such that

$$
\lim _{n \rightarrow \infty} \delta_{n}=\lim _{n \rightarrow \infty}\left[d\left(g x_{n+1}, g x_{n}\right)+d\left(g y_{n+1}, g y_{n}\right)\right]=\delta .
$$

We shall show that $\delta=0$. Suppose, to the contrary, that $\delta>0$. Then taking the limit as $n \rightarrow \infty$ (equivalently, $\delta_{n} \rightarrow \delta$ ) of both sides of (15) and remembering $\lim _{t \rightarrow r} \psi(t)>0$ for all $r>0$ and $\varphi$ is continuous, we have 


$$
\begin{aligned}
\phi(\delta) & =\lim _{n \rightarrow \infty} \phi\left(\delta_{n}\right) \leq \lim _{n \rightarrow \infty}\left[\phi\left(\delta_{n-1}\right)-2 \psi\left(\frac{\delta_{n-1}}{2}\right)\right] \\
& =\phi(\delta)-2 \lim _{\delta_{n-1} \rightarrow \delta} \psi\left(\frac{\delta_{n-1}}{2}\right)<\phi(\delta)
\end{aligned}
$$

a contradiction. Thus $\delta=0$, that is

$$
\lim _{n \rightarrow \infty} \delta_{n}=\lim _{n \rightarrow \infty}\left[d\left(g x_{n+1}, g x_{n}\right)+d\left(g y_{n+1}, g y_{n}\right)\right]=0 .
$$

Now, we will prove that $\left\{g x_{n}\right\}$ and $\left\{g y_{n}\right\}$ are Cauchy sequences. Suppose, to the contrary, that at least one of $\left\{g x_{n}\right\}$ or $\left\{g y_{n}\right\}$ is not Cauchy sequence. Then there exists an $\varepsilon>0$ for which we can find subsequences $\left\{g x_{n}(k)\right\}$, $\left\{g x_{m}(k)\right\}$ of $\left\{g x_{n}\right\}$ and $\left\{g y_{n}\left(k_{k}\right)\right\},\left\{g y_{m}\left(k_{k}\right)\right\}$ of $\left\{g y_{n}\right\}$ with $n(k)>m(k) \geq k$ such that

$$
d\left(g x_{n(k)}, g x_{m(k)}\right)+d\left(g y_{n(k)}, g y_{m(k)}\right) \geq \varepsilon .
$$

Further, corresponding to $m(k)$, we can choose $n(k)$ in such a way that it is the smallest integer with $n(k)>m(k)$ and satisfying (18). Then

$$
d\left(g x_{n(k)-1}, g x_{m(k)}\right)+d\left(g y_{n(k)-1}, g y_{m(k)}\right)<\varepsilon .
$$

Using (18), (19) and the triangle inequality, we have

$$
\begin{aligned}
\varepsilon & \leq r_{k}:=d\left(g x_{n(k)}, g x_{m(k)}\right)+d\left(g y_{n(k)}, g y_{m(k)}\right) \\
& \leq d\left(g x_{n(k)}, g x_{n(k)-1}\right)+d\left(g x_{n(k)-1}, g x_{m(k)}\right)+d\left(g y_{n(k)}, g y_{n(k)-1}\right)+d\left(g y_{n(k)-1}, g y_{m(k)}\right) \\
& \leq d\left(g x_{n(k)}, g x_{n(k)-1}\right)+d\left(g y_{n(k)}, g y_{n(k)-1}\right)+\varepsilon .
\end{aligned}
$$

Letting $k \rightarrow \infty$ and using (17), we get

$$
\lim _{k \rightarrow \infty} r_{k}=\lim _{k \rightarrow \infty}\left[d\left(g x_{n(k)}, g x_{m(k)}\right)+d\left(g y_{n(k)}, g y_{m(k)}\right]=\varepsilon .\right.
$$

By the triangle inequality

$$
\begin{aligned}
r_{k} & =d\left(g x_{n(k)}, g x_{m(k)}\right)+d\left(g y_{n(k)}, g y_{m(k)}\right) \\
& \leq d\left(g x_{n(k)}, g x_{n(k)+1}\right)+d\left(g x_{n(k)+1}, g x_{m(k)+1}\right)+d\left(g x_{m(k)+1}, g x_{m(k)}\right) \\
& +d\left(g y_{n(k)}, g y_{n(k)+1}\right)+d\left(g y_{n(k)+1}, g y_{m(k)+1}\right)+d\left(g y_{m(k)+1}, g y_{m(k)}\right) \\
& =\delta_{n(k)}+\delta_{m(k)}+d\left(g x_{n(k)+1}, g x_{m(k)+1}\right)+d\left(g y_{n(k)+1}, g y_{m(k)+1}\right) .
\end{aligned}
$$

Using the property of $\varphi$, we have

$$
\begin{aligned}
\phi\left(r_{k}\right) & =\phi\left(\delta_{n(k)}+\delta_{m(k)}+d\left(g x_{n(k)+1}, g x_{m(k)+1}\right)+d\left(g y_{n(k)+1}, g y_{m(k)+1}\right)\right) \\
& \leq \phi\left(\delta_{n(k)}+\delta_{m(k)}\right)+\phi\left(d\left(g x_{n(k)+1}, g x_{m(k)+1}\right)\right) \\
& +\phi\left(d\left(g y_{n(k)+1}, g y_{m(k)+1}\right)\right) .
\end{aligned}
$$

Since $n(k)>m(k)$, hence $g x_{n}\left({ }_{k}\right) \geqslant g x_{m}(k)$ and $g y_{n}(k) \geqslant g y_{m}(k)$. Using (3) and (4), we get

$$
\begin{aligned}
\phi\left(d\left(g x_{n(k)+1}, g x_{m(k)+1}\right)\right) & =\phi\left(d\left(F\left(x_{n(k)}, y_{n(k)}\right), F\left(x_{m(k)}, y_{m(k)}\right)\right)\right) \\
& \leq \frac{1}{2} \phi\left(d\left(g x_{n(k)}, g x_{m(k)}\right)+d\left(g y_{n(k)}, g y_{m(k)}\right)\right) \\
& -\psi\left(\frac{d\left(g x_{n(k)}, g x_{m(k)}\right)+d\left(g y_{n(k)}, g y_{m(k)}\right)}{2}\right) \\
& =\frac{1}{2} \phi\left(r_{k}\right)-\psi\left(\frac{r_{k}}{2}\right) .
\end{aligned}
$$


By the same way, we also have

$$
\begin{aligned}
\phi\left(d\left(g y_{m(k)+1}, g y_{n(k)+1}\right)\right) & =\phi\left(d\left(F\left(y_{m(k)}, x_{m(k)}\right), F\left(y_{n(k)}, x_{n(k)}\right)\right)\right) \backslash \\
& \leq \frac{1}{2} \phi\left(d\left(g y_{m(k)}, g y_{n(k)}\right)+d\left(g x_{m(k)}, g x_{n(k)}\right)\right) \\
& -\psi\left(\frac{d\left(g y_{m(k)}, g y_{n(k)}\right)+d\left(g x_{m(k)}, g x_{n(k)}\right)}{2}\right) \\
& =\frac{1}{2} \phi\left(r_{k}\right)-\psi\left(\frac{r_{k}}{2}\right) .
\end{aligned}
$$

Inserting (22) and (23) in (21), we have

$$
\phi\left(r_{k}\right) \leq \phi\left(\delta_{n(k)}+\delta_{m(k)}\right)+\phi\left(r_{k}\right)-2 \psi\left(\frac{r_{k}}{2}\right) .
$$

Letting $k \rightarrow \infty$ and using (17) and (20), we get

$$
\phi(\varepsilon) \leq \phi(0)+\phi(\varepsilon)-2 \lim _{k \rightarrow \infty} \psi\left(\frac{r_{k}}{2}\right)=\phi(\varepsilon)-2 \lim _{r_{k} \rightarrow \varepsilon} \psi\left(\frac{r_{k}}{2}\right)<\phi(\varepsilon)
$$

a contradiction. This shows that $\left\{g x_{n}\right\}$ and $\left\{g y_{n}\right\}$ are Cauchy sequences.

Since $X$ is a complete metric space, there exist $x, y \in X$ such that

$$
\lim _{n \rightarrow \infty} F\left(x_{n}, y_{n}\right)=\lim _{n \rightarrow \infty} g x_{n}=x \text { and } \lim _{n \rightarrow \infty} F\left(y_{n}, x_{n}\right)=\lim _{n \rightarrow \infty} g y_{n}=\gamma .
$$

Since $F$ and $g$ are compatible mappings, we have

$$
\lim _{n \rightarrow \infty} d\left(g\left(F\left(x_{n}, y_{n}\right)\right), F\left(g x_{n}, g y_{n}\right)\right)=0
$$

and

$$
\lim _{n \rightarrow \infty} d\left(g\left(F\left(y_{n}, x_{n}\right)\right), F\left(g y_{n}, g x_{n}\right)\right)=0
$$

We now show that $g x=F(x, y)$ and $g y=F(y, x)$. Suppose that the assumption (a) holds. For all $n \geq 0$, we have,

$$
d\left(g x, F\left(g x_{n}, g y_{n}\right)\right) \leq d\left(g x, g\left(F\left(x_{n}, y_{n}\right)\right)\right)+d\left(g\left(F\left(x_{n}, y_{n}\right)\right), F\left(g x_{n}, g y_{n}\right) .\right.
$$

Taking the limit as $n \rightarrow \infty$, using (4), (24), (25) and the fact that $F$ and $g$ are continuous, we have $d(g x, F(x, y))=0$.

Similarly, using (4), (24), (26) and the fact that $F$ and $g$ are continuous, we have $d(g y$, $F(y, x))=0$.

Combining the above two results we get

$$
g x=F(x, y) \text { and } g y=F(y, x) .
$$

Finally, suppose that (b) holds. By (5), (6) and (24), we have $\left\{g x_{n}\right\}$ is a non-decreasing sequence, $g x_{n} \rightarrow x$ and $\left\{g y_{n}\right\}$ is a non-increasing sequence, $g y_{n} \rightarrow y$ as $n \rightarrow \infty$. Hence, by assumption (b), we have for all $n \geq 0$,

$$
g x_{n} \preccurlyeq x \text { and } g y_{n} \preccurlyeq y \text {. }
$$

Since $F$ and $g$ are compatible mappings and $g$ is continuous, by (25) and (26) 
we have

$$
\lim _{n \rightarrow \infty} g\left(g x_{n}\right)=g x=\lim _{n \rightarrow \infty} g\left(F\left(x_{n}, y_{n}\right)\right)=\lim _{n \rightarrow \infty} F\left(g x_{n}, g y_{n}\right)
$$

and,

$$
\lim _{n \rightarrow \infty} g\left(g y_{n}\right)=g y=\lim _{n \rightarrow \infty} g\left(F\left(y_{n}, x_{n}\right)\right)=\lim _{n \rightarrow \infty} F\left(g y_{n}, g x_{n}\right) .
$$

Now we have

$$
d(g x, F(x, y)) \leq d\left(g x, g\left(g x_{n+1}\right)\right)+d\left(g\left(g x_{n+1}\right), F(x, y)\right) .
$$

Taking $n \rightarrow \infty$ in the above inequality, using (4) and (21) we have,

$$
\begin{aligned}
d(g x, F(x, y)) & \leq \lim _{n \rightarrow \infty} d\left(g x, g\left(g x_{n+1}\right)\right)+\lim _{n \rightarrow \infty} d\left(g\left(F\left(x_{n}, y_{n}\right)\right), F(x, y)\right) \\
& \left.\leq \lim _{n \rightarrow \infty} d\left(F\left(g x_{n}, g y_{n}\right)\right), F(x, y)\right)
\end{aligned}
$$

Using the property of $\varphi$, we get

$$
\left.\phi(d(g x, F(x, y))) \leq \lim _{n \rightarrow \infty} \phi\left(d\left(F\left(g x_{n}, g y_{n}\right)\right), F(x, y)\right)\right)
$$

Since the mapping $g$ is monotone increasing, using (3), (27) and (30), we have for all $n \geq 0$,

$$
\begin{aligned}
\phi(d(g x, F(x, y))) & \leq \lim _{n \rightarrow \infty} \frac{1}{2} \phi\left(d\left(g g x_{n}, g x\right)+d\left(g y_{n}, g g y\right)\right) \\
& -\lim _{n \rightarrow \infty} \psi\left(\frac{d\left(g g x_{n}, g x\right)+d\left(g g y_{n}, g y\right)}{2}\right) .
\end{aligned}
$$

Using the above inequality, using (24) and the property of $\psi$, we get $\varphi(d(g x, F(x, y)))=0$, thus $d(g x, F(x, y))=0$. Hence $g x=F(x, y)$.

Similarly, we can show that $g y=F(y, x)$. Thus we proved that $F$ and $g$ have a coupled coincidence point.

Corollary $3.1[11]$ Let $(X, \preccurlyeq)$ be a partially ordered set and suppose there is a metric $d$ on $X$ such that $(X, d)$ is a complete metric space. Let $F: X \times X \rightarrow X$ be a mapping having the mixed monotone property on $X$ such that there exist two elements $x_{0}, y_{0} \in X$ with

$$
x_{0} \preccurlyeq F\left(x_{0}, y_{0}\right) \text { and } y_{0} \succcurlyeq F\left(y_{0}, x_{0}\right) .
$$

Suppose there exist $\varphi \in \Phi$ and $\psi \in \Psi$ such that

$$
\phi(d(F(x, y), F(u, v))) \leq \frac{1}{2} \phi(d(x, u)+d(y, v))-\psi\left(\frac{d(x, u)+d(y, v))}{2}\right)
$$

for all $x, y, u, v \in X$ with $x \geq u$ and $y \leq v$. Suppose either

(a) $F$ is continuous or

(b) $X$ has the following property.

(i) if a non-decreasing sequence $\left\{x_{n}\right\} \rightarrow x$, then $x_{n} \leqslant x$, for all $n$,

(ii) if a non-increasing sequence $\left\{y_{n}\right\} \rightarrow y$, then $y \leqslant y_{n}$, for all $n$,

then there exist $x, y \in X$ such that 


$$
x=F(x, y) \text { and } y=F(y, x)
$$

that is, F has a coupled fixed point in $X$.

Corollary 3.2 [11] Let $(X, \preccurlyeq)$ be a partially ordered set and suppose there is a metric $d$ on $X$ such that $(X, d)$ is a complete metric space. Let $F: X \times X \rightarrow X$ be a mapping having the mixed monotone property on $X$ such that there exist two elements $x_{0}, y_{0} \in X$ with

$$
x_{0} \preccurlyeq F\left(x_{0}, y_{0}\right) \text { and } y_{0} \succcurlyeq F\left(y_{0}, x_{0}\right) \text {. }
$$

Suppose there exists $\psi \in \Psi$ such that

$$
d(F(x, y), F(u, v)) \leq \frac{d(x, u)+d(y, v)}{2}-\psi\left(\frac{d(x, u)+d(y, v)}{2}\right)
$$

for all $x, y, u, v \in X$ with $x \geq u$ and $y \leq v$. Suppose either

(a) $F$ is continuous or

(b) $X$ has the following property:

(i) if a non-decreasing sequence $\left\{x_{n}\right\} \rightarrow x$, then $x_{n} \leqslant x$, for all $n$,

(ii) if a non-increasing sequence $\left\{y_{n}\right\} \rightarrow y$, then $y \leqslant y_{n}$, for all $n$,

then there exist $x, y \in X$ such that

$$
x=F(x, y) \text { and } y=F(y, x)
$$

that is, F has a coupled fixed point in $X$.

Proof. Take $\varphi(t)=t$ in Corollary 3.1, we get Corollary 3.2.

Corollary 3.3 [5] eses of Corollary 3.1, suppose that for Let $(X, \preccurlyeq)$ be a partially ordered set and suppose there is a metric $d$ on $X$ such that $(X, d)$ is a complete metric space. Let $F: X \times X \rightarrow X$ be a mapping having the mixed monotone property on $X$ such that there exist two elements $x_{0}, y_{0} \in X$ with

$$
x_{0} \preccurlyeq F\left(x_{0}, y_{0}\right) \text { and } y_{0} \succcurlyeq F\left(y_{0}, x_{0}\right) \text {. }
$$

Suppose there exists a real number $k \in[0,1)$ such that

$$
d(F(x, y), F(u, v)) \leq \frac{k}{2}[d(x, u)+d(y, v)]
$$

for all $x, y, u, v \in X$ with $x \geq u$ and $y \geq v$. Suppose either

(a) $F$ is continuous or

(b) $X$ has the following property.

(i) if a non-decreasing sequence $\left\{x_{n}\right\} \rightarrow x$, then $x_{n} \leqslant x$, for all $n$,

(ii) if a non-increasing sequence $\left\{y_{n}\right\} \rightarrow y$, then $y \leqslant y_{n}$, for all $n$,

then there exist $x, y \in X$ such that

$$
x=F(x, y) \quad \text { and } \quad y=F(y, x)
$$

that is, F has a coupled fixed point in $X$. 
Proof. Taking $\psi(t)=\frac{1-k}{2} t$ in Corollary 3.2.

\section{Uniqueness of coupled coincidence point}

In this section, we will prove the uniqueness of the coupled coincidence point. Note that if $(X, \preccurlyeq)$ is a partially ordered set, then we endow the product $X \times X$ with the following partial order relation, for all $(x, y),(u, v) \in X \times X$,

$$
(x, y) \preccurlyeq(u, v) \quad \Leftrightarrow \quad x \preccurlyeq u, y \succcurlyeq v .
$$

Theorem 4.1 In addition to hypotheses of Theorem 3.1, suppose that for every $(x, y)$, $(z, t)$ in $X \times X$, if there exists $a(u, v)$ in $X \times X$ that is comparable to $(x, y)$ and $(z, t)$, then $F$ has a unique coupled coincidence point.

Proof. From Theorem 3.1, the set of coupled coincidence points of $F$ and $g$ is nonempty. Suppose $(x, y)$ and $(z, t)$ are coupled coincidence points of $F$ and $g$, that is $g x=$ $F(x, y), g y=F(y, x), g z=F(z, t)$ and $g t=F(t, z)$. We are going to show that $g x=g z$ and $g y=g t$. By assumption, there exists $(u, v) \subset X \times X$ that is comparable to $(x, y)$ and $(z$, $t$ ). We define sequences $\left\{g u_{n}\right\},\left\{g v_{n}\right\}$ as follows

$$
u_{0}=u \quad v_{0}=v . \quad g u_{u+1}=F\left(u_{n}, v_{n}\right) \quad \text { and } g v_{n+1}=F\left(v_{n}, u_{n}\right) \quad \text { for all } n .
$$

Since $(u, v)$ is comparable with $(x, y)$, we may assume that $(x, y) \geqslant(u, v)=\left(u_{0}, v_{0}\right)$. Using the mathematical induction, it is easy to prove that

$$
(x, y) \succcurlyeq\left(u_{n}, v_{n}\right) \text { for all } n .
$$

Using (3) and (31), we have

$$
\begin{aligned}
\varphi\left(d\left(g x, g u_{n+1}\right)\right) & =\varphi\left(d\left(F(x, y), F\left(u_{n}, v_{n}\right)\right)\right) \\
& <\frac{1}{2} \varphi\left(d\left(x, u_{n}\right)+d\left(y, v_{n}\right)\right)-\psi\left(\frac{d\left(x, u_{n}\right)+d\left(y, v_{n}\right)}{2}\right)
\end{aligned}
$$

Similarly

$$
\begin{aligned}
\varphi\left(d\left(g v_{n+1}, g y\right)\right) & =\varphi\left(d\left(F\left(v_{n}, u_{n}\right), F(y, x)\right)\right) \\
& <\frac{1}{2} \varphi\left(d\left(v_{n}, \gamma\right)+d\left(u_{n}, x\right)\right)-\psi\left(\frac{d\left(v_{n}, y\right)+d\left(u_{n}, x\right)}{2}\right)
\end{aligned}
$$

Using (32), (33) and the property of $\phi$, we have

$$
\begin{aligned}
\varphi\left(d\left(g x, g u_{n+1}\right)+d\left(g y, g v_{n+1}\right)\right) & \leq \varphi\left(d\left(g x, g u_{n+1}\right)\right)+\varphi\left(d\left(g y, g v_{n+1}\right)\right) \\
& \leq \varphi\left(d\left(g x, g u_{n}\right)+d\left(g y, g v_{n}\right)\right) \\
& -2 \psi\left(\frac{d\left(g x, g u_{n}\right)+d\left(g y, g v_{n}\right)}{2}\right)
\end{aligned}
$$

which implies, using the property of $\psi$,

$$
\varphi\left(d\left(g x, g u_{n+1}\right)+d\left(g y, g v_{n+1}\right)\right) \leq \varphi\left(d\left(g x, g u_{n}\right)+d\left(g y, g v_{n}\right)\right) .
$$

Thus, using the property of $\varphi$,

$$
d\left(g x, g u_{n+1}\right)+d\left(g y, g v_{n+1}\right) \leq d\left(g x, g u_{n}\right)+d\left(g y, g v_{n}\right) .
$$


That is the sequence $\left\{d\left(g x, g u_{n}\right)+d\left(g y, g v_{n}\right)\right\}$ is decreasing. Therefore, there exists $\alpha \geq$ 0 such that

$$
\lim _{n \rightarrow \infty}\left[d\left(g x, g u_{n}\right)+d\left(g y, g v_{n}\right)\right]=\alpha .
$$

We will show that $\alpha=0$. Suppose, to the contrary, that $\alpha>0$. Taking the limit as $n$ $\rightarrow \infty$ in (34), we have, using the property of $\psi$,

$$
\varphi(\alpha) \leq \varphi(\alpha)-2 \lim _{n \rightarrow \infty} \psi\left(\frac{d\left(g x, g u_{n}\right)+d\left(g y, g v_{n}\right)}{2}\right)<\varphi(\alpha)
$$

a contradiction. Thus. $\alpha=0$, that is,

$$
\lim _{n \rightarrow \infty}\left[d\left(g x, g u_{n}\right)+d\left(g y, g v_{n}\right)\right]=0 .
$$

It implies

$$
\lim _{n \rightarrow \infty} d\left(g x, g u_{n}\right)=\lim _{n \rightarrow \infty} d\left(g y, g v_{n}\right)=0 .
$$

Similarly, we show that

$$
\lim _{n \rightarrow \infty} d\left(g z, g u_{n}\right)=\lim _{n \rightarrow \infty} d\left(g t, g v_{n}\right)=0 .
$$

Using (36) and (37) we have $g x=g z$ and $g y=g t$.

Corollary 4.1 [11]In addition to hypotheses of Corollary 3.1, suppose that for every ( $x$, $y),(z, t)$ in $X \times X$, if there exists a $(u, v)$ in $X \times X$ that is comparable to $(x, y)$ and $(z, t)$, then $F$ has a unique coupled fixed point.

\section{Example}

Example 5.1 Let $X=[0,1]$. Then $(X, \leq)$ is a partially ordered set with the natural ordering of real numbers. Let

$$
d(x, y)=|x-y| \quad \text { for } \quad x, y \in[0,1] .
$$

Then $(X, d)$ is a complete metric space.

Let $g: X \rightarrow X$ be defined as

$$
g x=x^{2}, \text { for all } x \in X,
$$

and let $F: X \times X \rightarrow X$ be defined as

$$
F(x, y)= \begin{cases}\frac{x^{2}-y^{2}}{3}, & \text { if } x \geq y, \\ 0, & \text { if } x<y .\end{cases}
$$

$F$ obeys the mixed g-monotone property.

Let $\varphi:[0, \infty) \rightarrow[0, \infty)$ be defined as

$$
\phi(t)=\frac{3}{4} t, \quad \text { for } \quad t \in[0, \infty) .
$$

and let $\psi:[0, \infty) \rightarrow[0, \infty)$ be defined as

$$
\psi(t)=\frac{1}{4} t, \quad \text { for } \quad t \in[0, \infty) .
$$


Let $\left\{x_{n}\right\}$ and $\left\{y_{n}\right\}$ be two sequences in $X$ such that $\lim _{n \rightarrow \infty} F\left(x_{n}, y_{n}\right)=a, \lim _{n \rightarrow \infty} g x_{n}=$ $a, \lim _{n \rightarrow \infty} F\left(y_{n}, x_{n}\right)=b$ and $\lim _{n \rightarrow \infty} g y_{n}=b$ Then obviously, $a=0$ and $b=0$. Now, for all $n \geq 0$,

$$
\begin{gathered}
g x_{n}=x_{n}^{2}, g y_{n}=y_{n}^{2} \\
F\left(x_{n}, y_{n}\right)= \begin{cases}\frac{x_{n}^{2}-y_{n}^{2}}{3}, & \text { if } x_{n} \geq y_{n} \\
0, & \text { if } x_{n}<y_{n} .\end{cases}
\end{gathered}
$$

and

$$
F\left(y_{n}, x_{n}\right)= \begin{cases}\frac{y_{n}^{2}-x_{n}^{2}}{3}, & \text { if } y_{n} \geq x_{n} \\ 0, & \text { if } y_{n}<x_{n} .\end{cases}
$$

Then it follows that,

$$
\lim _{n \rightarrow \infty} d\left(g\left(F\left(x_{n}, y_{n}\right)\right), F\left(g x_{n}, g y_{n}\right)\right)=0
$$

and

$$
\lim _{n \rightarrow \infty} d\left(g\left(F\left(y_{n}, x_{n}\right)\right), F\left(g y_{n}, g x_{n}\right)\right)=0,
$$

Hence, the mappings $F$ and $g$ are compatible in $X$. Also, $x_{0}=0$ and $y_{0}=c(>0)$ are two points in $X$ such that

$$
g x_{0}=g(0)=0=F(0, c)=F\left(x_{0}, y_{0}\right)
$$

and

$$
g \gamma_{0}=g(c)=c^{2} \geq \frac{c^{2}}{3}=F(c, 0)=F\left(y_{0}, x_{0}\right) .
$$

We next verify the contraction (3). We take $x, y, u, v, \in X$, such that $g x \geq g u$ and $g y \leq$ gv, that is, $x^{2} \geq u^{2}$ and $y^{2} \leq v^{2}$.

We consider the following cases:

Case 1. $x \geq y, u \geq v$. Then,

$$
\begin{aligned}
\phi(d(F(x, y), F(u, v))) & =\frac{3}{4}[d(F(x, y), F(u, v)] \\
& =\frac{3}{4}\left[d\left(\frac{x^{2}-y^{2}}{3}, \frac{u^{2}-v^{2}}{3}\right)\right] \\
& =\frac{3}{4}\left|\frac{\left(x^{2}-y^{2}\right)-\left(u^{2}-v^{2}\right)}{3}\right| \\
& =\frac{3}{4} \frac{\left|x^{2}-u^{2}\right|+\left|y^{2}-v^{2}\right|}{3} \\
& =\frac{1}{2}\left(\frac{d(g x, g u)+d(g y, g v)}{2}\right) \\
& =\frac{3}{4}\left(\frac{d(g x, g u)+d(g y, g v)}{2}\right) \\
& -\frac{1}{4}\left(\frac{d(g x, g u)+d(g y, g v)}{2}\right) \\
& =\frac{3}{8}(d(g x, g u)+d(g y, g v)) \\
& -\frac{1}{4}\left(\frac{d(g x, g u)+d(g y, g v)}{2}\right) \\
& =\frac{1}{2} \phi(d(g x, g u)+d(g y, g v)) \\
& -\psi\left(\frac{d(g x, g u)+d(g y, g v)}{2}\right)
\end{aligned}
$$


Case 2. $x \geq y, u<v$.Then

$$
\begin{aligned}
\phi(d(F(x, y), F(u, v)) & =\frac{3}{4}[d(F(x, y), F(u, v)] \\
& =\frac{3}{4}\left[d\left(\frac{x^{2}-y^{2}}{3}, 0\right)\right] \\
& =\frac{3}{4} \frac{\left|x^{2}-y^{2}\right|}{3} \\
& =\frac{3}{4} \frac{\left|v^{2}+x^{2}-y^{2}-u^{2}\right|}{3} \\
& =\frac{3}{4} \frac{\left|\left(v^{2}-y^{2}\right)-\left(u^{2}-x^{2}\right)\right|}{3} \\
& \leq \frac{3}{4} \frac{\left|v^{2}-y^{2}\right|+\left|u^{2}-x^{2}\right|}{3} \\
& =\frac{3}{4}\left(\frac{\left|u^{2}-x^{2}\right|+\left|y^{2}-v^{2}\right|}{3}\right) \\
& =\frac{1}{2}\left(\frac{\left|u^{2}-x^{2}\right|+\left|y^{2}-v^{2}\right|}{2}\right) \\
& =\frac{1}{2}\left(\frac{d(g x, g u)+d(g y, g v)}{2}\right) \\
& =\frac{3}{4}\left(\frac{d(g x, g u)+d(g y, g v)}{2}\right) \\
& -\frac{1}{4}\left(\frac{d(g x, g u)+d(g y, g v)}{2}\right) \\
& =\frac{3}{8}(d(g x, g u)+d(g y, g v)) \\
& -\frac{1}{4}\left(\frac{d(g x, g u)+d(g y, g v)}{2}\right. \\
& =\frac{1}{2} \phi(d(g x, g u)+d(g y, g v)) \\
& -\psi\left(\frac{d(g x, g u)+d(g y, g v)}{2}\right)
\end{aligned}
$$

Case 3. $x<y$ and $u \geq v$. Then

$$
\begin{aligned}
\phi(d(F(x, y), F(u, v))) & =\frac{3}{4}\left[d\left(0, \frac{u^{2}-v^{2}}{3}\right)\right] \\
& =\frac{3}{4} \frac{\left|u^{2}-v^{2}\right|}{3} \\
& =\frac{3}{4} \frac{\left|u^{2}+x^{2}-v^{2}-x^{2}\right|}{3} \\
& =\frac{3}{4} \frac{\left|\left(x^{2}-v^{2}\right)+\left(u^{2}-x^{2}\right)\right|}{3}(\text { since } y>x) \\
& \leq \frac{3}{4} \frac{\left|y^{2}-v^{2}\right|+\left|u^{2}-x^{2}\right|}{3} \\
& =\frac{1}{2}\left(\frac{\left|u^{2}-x^{2}\right|+\left|y^{2}-v^{2}\right|}{2}\right) \\
& =\frac{1}{2}\left(\frac{d(g x, g u)+d(g y, g v)}{2}\right) \\
& =\frac{3}{4}\left(\frac{d(g x, g u)+d(g y, g v)}{2}\right) \\
& -\frac{1}{4}\left(\frac{d(g x, g u)+d(g y, g v)}{2}\right) \\
& =\frac{3}{8}(d(g x, g u)+d(g y, g v)) \\
& -\frac{1}{4}\left(\frac{d(g x, g u)+d(g y, g v)}{2}\right) \\
& =\frac{1}{2} \phi(d(g x, g u)+d(g y, g v)) \\
& -\psi\left(\frac{d(g x, g u)+d(g y, g v)}{2}\right)
\end{aligned}
$$


Case 4. $x<y$ and $u<v$ with $x^{2} \leq u^{2}$ and $y^{2} \geq v^{2}$. Then, $F(x, y)=0$ and $F(u, v)=0$, that is,

$$
\phi(d(F(x, y), F(u, v)))=\phi(d(0,0))=\phi(0)=0 .
$$

\section{Therefore all conditions of Theorem 3.1 are satisfied. Thus the conclusion follows.}

\section{Acknowledgements}

The authors would like to thank the referees for the invaluable comments that improved this paper.

\section{Authors' contributions}

The authors have been working together on each step of the paper such as the literature review, results and examples.

\section{Competing interests}

The authors declare that they have no competing interests.

Received: 18 March 2011 Accepted: 30 August 2011 Published: 30 August 2011

\section{References}

1. Abbas, M, Ali Khan, M, Radenovic, S: Common coupled fixed point theorems in cone metric spaces for $w$-compatible mappings. Appl Math Comput. 217, 195-201 (2010). doi:10.1016/j.amc.2010.05.042

2. Abbas, M, Ali Khan, M, Nazir, T: Coupled common fixed point results in two generalized metric spaces. Appl Math Comput. 217, 6328-6336 (2011). doi:10.1016/j.amc.2011.01.006

3. Agarwal, RP, El-Gebeily, MA, O'Regan, D: Generalized contractions in partially ordered metric spaces. Appl Anal. 87, 1-8 (2008). doi:10.1080/00036810701714164

4. Altun, I, Erduran, A: Fixed point theorems for monotone mappings on partial metric spaces. Fixed Point Theory Appl 2011 (2011). Article ID 508730

5. Bhaskar, TG, Lakshmikantham, V: Fixed point theorems in partially ordered metric spaces and applications. Nonlinear Anal: Theorey Methods Appl. 65, 1379-1393 (2006). doi:10.1016/j.na.2005.10.017

6. Choudhury, BS, Kundu, A: A coupled coincidence point result in partially ordered metric spaces for compatible mappings. Nonlinear Anal. 73, 2524-2531 (2010). doi:10.1016/j.na.2010.06.025

7. Hussain, N, Shah, MH, Kutbi, MA: Coupled coincidence point theorems for nonlinear contractions in partially ordered quasi-metric spaces with a Q-function. Fixed Point Theory Appl 2011, 21 (2011). Article ID 703938. doi:10.1186/16871812-2011-21

8. Khamsi, MA, Hussain, N: KKM mappings in metric type spaces. Nonlinear Anal: Theory Methods Appl. 73, 3123-3129 (2010). doi:10.1016/j.na.2010.06.084

9. Khamsi, MA, Kirk, W: An Introduction to Metric Spaces and Fixed Point Theory, Pure and Applied Mathematics. WileyInterscience, New York (2001)

10. Lakshmikantham, V Ćirifić, L: Coupled fixed point theorems for nonlinear contractions in partially ordered metric spaces. Nonlinear Anal: Theorey Methods Appl. 70(12), 4341-4349 (2009). doi:10.1016/j.na.2008.09.020

11. Luong, NV, Thuan, NX: Coupled fixed point in partially ordered metric spaces and applications. Nonlinear Anal: Theorey Methods Appl. 74, 983-992 (2011). doi:10.1016/j.na.2010.09.055

12. Nieto, JJ, Rodriguez-Lopez, R: Contractive mapping theorems in partially ordered sets and applications to ordinary differential equations. Order. 22, 223-239 (2005). doi:10.1007/s11083-005-9018-5

13. Nieto, JJ, Lopez, RR: Existence and uniqueness of fixed point in partially ordered sets and applications to ordinary differential equations. Acta Math Sinica Engl Ser. 23(12), 2205-2212 (2007). doi:10.1007/s10114-005-0769-0

14. Ran, ACM, Reurings, MCB: A fixed point theorem in partially ordered sets and some applications to matrix equations. Proc Am Math Soc. 132, 1435-1443 (2004). doi:10.1090/S0002-9939-03-07220-4

15. Sabetghadam, F, Masiha, HP, Sanatpour, AH: Some coupled fixed point theorems in cone metric spaces. Fixed Point Theory Appl 2009 (2009). Article ID 125426

16. Ray, BK: On Ćirić's fixed point theorem. Fund Math. XCIV, 221-229 (1977)

doi:10.1186/1687-1812-2011-44

Cite this article as: Alotaibi and Alsulami: Coupled coincidence points for monotone operators in partially ordered metric spaces. Fixed Point Theory and Applications 2011 2011:44. 